Sri Lanka J. Aquat. Sci. 16 (2011): 01-10

\title{
Morphological differentiation of two cichlid species in Sri Lanka using truss networks
}

\author{
G.K.A.W. FERNANDO and U.S. AMARASINGHE* \\ Department of Zoology, University of Kelaniya, Kelaniya 11600, Sri \\ Lanka \\ *Corresponding author (zoousa@kln.ac.lk)
}

\begin{abstract}
Morphometric characterization using truss network systems has been widely used for fish identification and stock identification. In Sri Lanka, differentiation of Oreochromis mossambicus and O. niloticus, the two major species in reservoir fishery, using conventional morphometric characteristic and phenotypic variations is problematic, due to the reasons that both species share somewhat similar body shape characteristics and that the populations of the two species have mixed characteristics as a result of introgressive hybridization. In the present study, an attempt was made to employ truss network analysis to differentiate $O$. mossambicus and $O$. niloticus. Truss measurements of 100 specimens of $O$. mossambicus from Negombo lagoon and 100 specimens of $O$. niloticus from Baira lake were analyzed using principal component analysis (PCA). Before the analysis, two approaches of data transformation were employed to minimize to eliminate any size effect in the data set of truss measurements. It was concluded that the data standardization method using a geometric mean regression techniques on the logarithms of truss length and total length was more effective for morphometric differentiation of the two cichlid species than using ratio of truss length to standard length for data transformation.
\end{abstract}

\section{Introduction}

Morphometric characterization is a powerful tool in fish taxonomy. However, conventional morphometric analyses such as length-weight relationships are not sufficient for morphometric characterization of fish species which are more or less morphometrically similar. As an alternative, a system of morphometric measurements called "Truss Network System" (Strauss and Bookstein (1982) has been increasingly used for species identification and especially for stock differentiation (Turan 1999).

Truss network (TN) is a series of measurements between morphological landmarks that form a regular pattern of connected quadrilaterals or cells across the body form (Turan 1999). Several studies are 
reported on the use of TN system for quantifying shape characterization of fish. The TN systems have been used to investigate shape characteristics of Oreochromis niloticus (Hockaday et al. 2000). Multivariate analysis was performed using truss morphometrics to study the differences among 6 species of family Serranidae (Cavalcanti et al. 1999). Strauss and Bookstein (1982) have compared traditional morphometric character sets of Cottus kalamathensis and Cottus pitensis and have shown that truss character sets were more effective than traditional character sets.

Oreochromis mossambicus and O. niloticus were introduced to Sri Lankan waters during the second half of the last century to develop inland fisheries (De Silva, 1988; Amarasinghe 1998). The body shape characteristics of $O$. niloticus and $O$. mossambicus are somewhat similar, although $O$. niloticus has a relatively deeper body than $O$. mossambicus. These two species are known to exhibit introgressive hybridization (De Silva and Ranasinghe 1989; Amarasinghe and De Silva 1996), and as such, populations of the two species have mixed characteristics. Differentiation of the two species using conventional morphometric characteristic and phenotypic variations is therefore problematic. Hence, it is necessary to use an effective method for morphological differentiation of the two cichlid species. This is of particular importance because body shape characteristics are useful not only for species differentiation but also for determining the catchability in fishing nets because gillnet selectivity is especially influenced by body shape characteristics of fish.

As TN analysis is known effective for differentiating morphologically similar species, in the present study, an attempt was made to employ TN analysis to differentiate $O$. mossambicus and $O$. niloticus.

\section{Materials and Methods}

Hundred specimens of $O$. mossambicus from Negombo lagoon (Location: $7^{\circ} 09^{\prime} 16^{\prime}$ ' N, 79'52'44' ' E) and 100 specimens of $O$. niloticus from Baira lake (Location: 6 ${ }^{\circ} 54^{\prime} 9^{\prime}$ ' $\mathrm{N}, 7^{\circ} 54^{\prime} 33^{\prime}$ ' E) were obtained from cast net catches during July - October 2008. Samples were packed in ice and they were taken to the laboratory for morphometric analyses.

From each specimen, standard length from the tip of the upper jaw to the base of the caudal peduncle and total length from the tip of the upper jaw to the end of the caudal fin were taken. A truss network was then constructed between landmark points. Eighteen truss lengths between 9 homologous landmarks on the left side of each fish were measured to the nearest $0.01 \mathrm{~cm}$ using a vernier caliper (Figure 1). Eight measurements were made on the head region and 10 were made in a truss network distributed over the rest of the body form. Each fish was placed on a board and each landmark was marked by piercing a pin. The standard length, total length and truss lengths measured are listed in Table 1. 


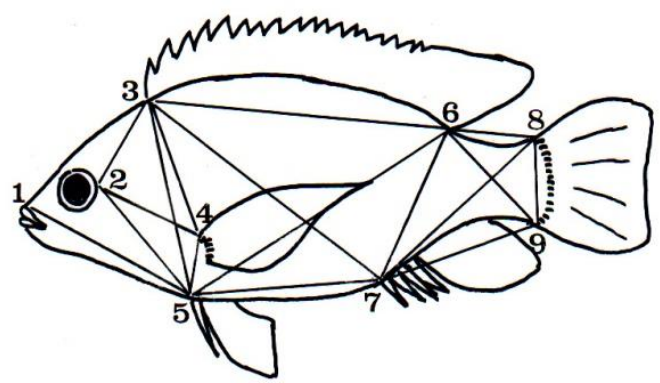

Figure 1. Nine landmark points used for truss measurements of two Oreochromis species. Landmark points refer to: 1. Snout; 2. Posterior point of the eye; 3. Origin of dorsal fin; 4. Origin of pectoral fin; 5 . Origin of pelvic fin; 6. Posterior end of dorsal fin; 7. Origin of anal fin; 8. Dorsal attachment of the caudal fin to the tail; and 9. Ventral attachment of the caudal fin to the tail (Redrawn after Hockaday et al. 2000).

Table 1. Measurements used to examine morphological variations among $O$. mossambicus and $O$. niloticus. Pin numbers are as indicated in Figure 1.

\begin{tabular}{|c|c|c|}
\hline Character No. & Pin No. & Character Description \\
\hline 1 & & Standard length \\
\hline 2 & & Total length \\
\hline 3 & $1-3$ & Snout to origin of dorsal fin \\
\hline 4 & $1-5$ & Snout to origin of pelvic fin \\
\hline 5 & $2-3$ & Posterior point of the eye to origin of dorsal fin \\
\hline 6 & $2-4$ & Posterior point of the eye to origin of pectoral fin \\
\hline 7 & $2-5$ & Posterior point of the eye to origin of pelvic fin \\
\hline 8 & $3-5$ & Origin of dorsal fin to origin of pelvic fin \\
\hline 9 & $3-4$ & Origin of dorsal fin to origin of pectoral fin \\
\hline 10 & $4-5$ & Origin of pectoral fin to origin of pelvic fin \\
\hline 11 & $5-6$ & Origin of pelvic fin to posterior end of dorsal fin \\
\hline 12 & $3-7$ & Origin of dorsal fin to origin of anal fin \\
\hline 13 & $3-6$ & Origin of dorsal fin to posterior end of dorsal fin \\
\hline 14 & $5-7$ & Origin of pelvic fin to origin of anal fin \\
\hline 15 & $7-6$ & Origin of anal fin to posterior end of dorsal fin \\
\hline 16 & $7-9$ & Origin of anal fin to ventral attachment of the caudal fin to tail \\
\hline 17 & $6-8$ & $\begin{array}{l}\text { Posterior end of the dorsal fin to dorsal attachment of the } \\
\text { caudal fin to tail }\end{array}$ \\
\hline 18 & $7-8$ & Origin of anal fin to dorsal attachment of the caudal fin to tail \\
\hline 19 & $6-9$ & $\begin{array}{l}\text { Posterior end of the dorsal fin to ventral attachment of the } \\
\text { caudal fin to tail }\end{array}$ \\
\hline 20 & $8-9$ & $\begin{array}{l}\text { Dorsal attachment of the caudal fin to tail to ventral attachment } \\
\text { of the caudal fin }\end{array}$ \\
\hline
\end{tabular}


The following two approaches of data transformation were employed to eliminate any size effect in the data set of truss measurements. In the first approach, truss measurements were transformed as follows:

Standard measurement $=\mathrm{LT} / \mathrm{SL}$

where LT is the truss length, SL is the standard length.

In the second approach, prior to multivariate analysis, all the morphometric measurements were standardized $\left(\mathrm{LT}_{\mathrm{s}}(\mathrm{i})\right.$ ) for fish size using the method of Senar et al. (1994) and Doherty and McCarthy (2004) as follows:

$$
\operatorname{LTs}_{(\mathrm{i})}=\log _{10} \mathrm{LT}_{(\mathrm{i})}\left[\frac{\log _{10} \mathrm{TL}_{(\mathrm{m})}}{\log _{10} \mathrm{TL}_{(\mathrm{i})}}\right]^{\mathrm{b}}
$$

where TL is the total length, $\mathrm{LT}_{(\mathrm{i})}$ is the truss length of $\mathrm{i}^{\text {th }}$ fish, $\mathrm{TL}_{\mathrm{m}}$ is the overall mean total length and $\mathrm{b}$ is the slope, within areas of the geometric mean regression on the logarithms of LT and TL. This regression model was chosen because none of these variables could be considered independent or explanatory. In this data transformation, total length and standard length were excluded.

It is expected that the absolute value of correlation coefficient would decrease after size correlation. Also, variables highly correlated after the size effect removal would be considered redundant and the data set could be reduced (Murta 2000). Pearson's correlation coefficients (r) between each pair of characters were used to check if the data transformation is effective in reducing the influence of size in the measurements (Murta 2000). The morphometric data transformed as LT/SL (equation 1), and those which were standardized for fish size using equation (2), were subjected to pair-wise comparison separately. Correlation matrices were determined between each pair of morphometric characteristics standardized according to equation (1), and equation (2) separately. Principal component analysis (PCA), which combines and summarizes the variables into a smaller number of principal components which are a linear combination of the variables, was employed to describe the shape variations in the pooled sample (Parsons et al. 2003). PCA was also performed separately for LT/SL transformed data (according to equation 1) and morphometric data which were transformed to remove size effect (according to equation 2).

All statistical analyses were carried out using MINITAB (version 14) and Primer (version 5) statistical software packages.

\section{Results}

The mean, standard error and range of each morphometric characteristic of the specimens of $O$. mossambicus in Negombo lagoon and $O$. niloticus in Baira lake are given in Table 2.Correlation matrix of morphometric data transformed as LT/SL for $O$. mossambicus in Negombo Lagoon and $O$. niloticus in Beira Lake are given in Table 3. 
Table 2. Summary of morphometric characteristic (in $\mathrm{cm}$ ) for samples of O. mossambicus in Negombo lagoon and O. niloticus from Lake. SE Standard Error; Min - Minimum value; Max - Maximum value.

\begin{tabular}{|c|c|c|c|c|c|c|c|c|}
\hline \multirow[t]{2}{*}{ Character Description } & \multicolumn{4}{|c|}{ O. mossambicus } & \multicolumn{4}{|c|}{ O. niloticus } \\
\hline & Mean & SE & Min & Max & Mean & SE & Min & Max \\
\hline Standard length & 7.61 & 0.17 & 5.50 & 13.90 & 8.96 & 0.27 & 5.40 & 19.50 \\
\hline Total length & 9.85 & 0.22 & 6.20 & 18.00 & 11.30 & 0.35 & 1.20 & 24.50 \\
\hline Snout to origin of dorsal fin & 2.09 & 0.05 & 1.45 & 3.65 & 2.63 & 0.08 & 1.60 & 5.40 \\
\hline Snout to origin of pelvic fin & 2.81 & 0.06 & 2.00 & 4.75 & 3.25 & 0.10 & 2.00 & 6.90 \\
\hline Posterior point of the eye to origin of dorsal fin & 1.46 & 0.03 & 1.00 & 2.40 & 1.78 & 0.05 & 1.10 & 3.94 \\
\hline Posterior point of the eye to origin of pectoral fin & 1.48 & 0.03 & 1.04 & 2.67 & 1.75 & 0.05 & 1.10 & 4.04 \\
\hline Posterior point of the eye to origin of pelvic fin & 2.25 & 0.05 & 1.00 & 4.04 & 2.77 & 0.08 & 1.07 & 5.90 \\
\hline Origin of dorsal fin to origin of pelvic fin & 2.87 & 0.07 & 1.70 & 5.20 & 3.62 & 0.11 & 2.06 & 7.60 \\
\hline Origin of dorsal fin to origin of pectoral fin & 2.03 & 0.05 & 1.39 & 3.70 & 2.52 & 0.07 & 1.09 & 5.16 \\
\hline Origin of pectoral fin to origin of pelvic fin & 0.96 & 0.02 & 0.70 & 1.90 & 1.23 & 0.04 & 0.70 & 2.60 \\
\hline Origin of pelvic fin to posterior end of dorsal fin & 4.29 & 0.10 & 3.06 & 8.30 & 5.37 & 0.17 & 1.23 & 12.30 \\
\hline Origin of dorsal fin to origin of anal fin & 4.03 & 0.09 & 2.80 & 7.10 & 4.95 & 0.16 & 2.80 & 11.00 \\
\hline Origin of dorsal fin to posterior end of dorsal fin & 4.42 & 0.10 & 3.10 & 8.27 & 5.27 & 0.17 & 2.90 & 12.30 \\
\hline Origin of pelvic fin to origin of anal fin & 2.30 & 0.06 & 1.04 & 4.28 & 3.33 & 0.10 & 1.76 & 7.10 \\
\hline Origin of anal fin to posterior end of dorsal fin & 2.53 & 0.06 & 1.80 & 4.90 & 2.85 & 0.10 & 1.50 & 7.10 \\
\hline Origin of anal fin to ventral attachment of the caudal fin to tail & 2.54 & 0.06 & 1.80 & 4.90 & 2.83 & 0.10 & 1.50 & 7.10 \\
\hline Posterior end of the dorsal fin to dorsal attachment of the caudal fin to tail & 0.95 & 0.02 & 0.60 & 1.90 & 1.21 & 0.04 & 0.70 & 2.74 \\
\hline Origin of anal fin to dorsal attachment of the caudal fin to tail & 3.03 & 0.08 & 2.10 & 5.96 & 3.44 & 0.11 & 1.40 & 8.20 \\
\hline Posterior end of the dorsal fin to ventral attachment of the caudal fin to tail & 1.52 & 0.04 & 1.0 & 2.76 & 1.82 & 0.06 & 1.04 & 4.08 \\
\hline $\begin{array}{l}\text { Dorsal attachment of the caudal fin to ventral attachment of the caudal fin } \\
\text { to tail }\end{array}$ & 1.20 & 0.07 & 0.80 & 8.00 & 1.31 & 0.43 & 0.70 & 3.10 \\
\hline
\end{tabular}



In $O$. mossambicus out of 153 pairs, only one $(0.65 \%)$ was significantly correlated while in $O$. niloticus, zero pairs $(0 \%)$ were significantly correlated at least at 0.05 probability level. These results indicated that LT/SL transformation has reduced size effect of the data set to a certain extent.

Table 3. Pearson's correlation matrix of LT/SL transformed morphometric characteristics of $O$. mossambicus in Negombo Lagoon (below the diagonal) and $O$. niloticus in Beira Lake (above the diagonal). The $\mathrm{r}$ values which are significant at least at 0.05 probability level are given in bold. The numbers of morphometric characters are as given in Table 1.

\begin{tabular}{|c|c|c|c|c|c|c|c|c|c|c|c|c|c|c|c|c|c|c|}
\hline & 3 & 4 & 5 & 6 & 7 & 8 & 9 & 10 & 11 & 12 & 13 & 14 & 15 & 16 & 17 & 18 & 19 & 20 \\
\hline 3 & & 0.25 & 0.32 & 0.29 & 0.27 & 0.36 & 0.14 & 0.22 & 0.02 & 0.11 & -0.09 & -0.06 & -0.02 & 0.00 & -0.12 & -0.12 & 0.02 & 0.25 \\
\hline 4 & 0.31 & & 0.11 & 0.21 & 0.21 & 0.37 & 0.08 & 0.39 & -0.1 & 0.12 & 0.16 & -0.03 & 0.04 & 0.12 & 0.05 & 0.10 & 0.12 & 0.11 \\
\hline 5 & 0.38 & 0.33 & & 0.14 & 0.24 & 0.31 & 0.20 & 0.17 & 0.13 & 0.34 & -0.17 & 0.13 & 0.00 & 0.03 & -0.14 & 0.02 & 0.07 & 0.14 \\
\hline 6 & 0.14 & 0.16 & 0.01 & & 0.29 & 0.29 & 0.01 & 0.21 & -0.15 & 0.09 & 0.04 & -0.03 & 0.12 & 0.24 & -0.03 & 0.09 & 0.12 & 0.23 \\
\hline 7 & 0.14 & 0.14 & 0.08 & 0.11 & & 0.37 & 0.08 & 0.43 & 0.15 & 0.26 & -0.47 & -0.09 & 0.20 & 0.26 & 0.02 & 0.08 & 0.19 & 0.23 \\
\hline 8 & 0.12 & 0.21 & 0.11 & 0.04 & 0.97 & & 0.41 & 0.52 & 0.11 & 0.44 & -0.01 & 0.07 & 0.26 & 0.34 & 0.05 & 0.04 & 0.19 & 0.33 \\
\hline 9 & 0.18 & 0.13 & 0.06 & 0.04 & 0.07 & 0.21 & & 0.20 & 0.08 & 0.16 & -0.03 & 0.08 & 0.09 & 0.13 & 0.14 & 0.00 & -0.07 & 0.10 \\
\hline 10 & 0.05 & 0.12 & 0.06 & -0.08 & 0.07 & 0.08 & 0.06 & & 0.04 & 0.42 & 0.06 & 0.09 & 0.23 & 0.19 & -0.08 & 0.03 & 0.14 & 0.14 \\
\hline 11 & -0.08 & -0.13 & -0.12 & 0.02 & 0.04 & -0.06 & -0.14 & -0.07 & & 0.14 & 0.10 & 0.19 & 0.07 & 0.09 & 0.02 & 0.01 & 0.02 & 0.12 \\
\hline 12 & 0.18 & 0.10 & 0.08 & -0.06 & -0.04 & 0.40 & 0.14 & 0.07 & 0.15 & & 0.14 & 0.26 & 0.01 & 0.21 & -0.08 & 0.09 & 0.14 & 0.14 \\
\hline 13 & -0.01 & -0.09 & -0.06 & 0.06 & 0.06 & 0.15 & -0.18 & 0.00 & 0.37 & 0.41 & & 0.17 & 0.03 & 0.04 & -0.02 & 0.02 & -0.57 & 0.06 \\
\hline 14 & 0.10 & 0.05 & 0.22 & 0.01 & -0.01 & 0.07 & 0.11 & 0.07 & 0.29 & 0.20 & 0.07 & & -0.16 & -0.17 & 0.04 & 0.12 & -0.06 & -0.07 \\
\hline 15 & 0.15 & 0.09 & 0.18 & 0.01 & 0.05 & 0.07 & 0.09 & -0.04 & 0.20 & 0.23 & 0.19 & 0.15 & & 0.74 & -0.14 & 0.38 & 0.19 & 0.32 \\
\hline 16 & 0.10 & 0.13 & 0.09 & 0.03 & 0.05 & 0.08 & 0.27 & -0.09 & 0.11 & 0.28 & 0.13 & 0.03 & 0.61 & & -0.04 & 0.49 & 0.23 & 0.46 \\
\hline 17 & -0.02 & 0.06 & 0.04 & -0.09 & 0.13 & 0.21 & -0.13 & -0.23 & 0.00 & 0.34 & 0.25 & 0.06 & 0.07 & 0.08 & & 0.06 & 0.07 & -0.11 \\
\hline 18 & 0.02 & 0.12 & -0.01 & 0.02 & 0.08 & 0.02 & 0.03 & -0.24 & 0.14 & 0.16 & 0.22 & 0.05 & 0.39 & 0.54 & 0.28 & & 0.14 & 0.24 \\
\hline 19 & 0.16 & 0.17 & 0.04 & 0.03 & 0.09 & 0.20 & 0.12 & -0.02 & 0.09 & 0.41 & 0.31 & 0.02 & 0.18 & 0.28 & 0.37 & 0.31 & & 0.21 \\
\hline 20 & 0.04 & -0.06 & 0.08 & 0.02 & 0.14 & 0.01 & 0.02 & 0.18 & 0.01 & 0.01 & 0.06 & -0.08 & -0.05 & 0.09 & 0.13 & 0.06 & 0.02 & \\
\hline
\end{tabular}



G.K.A.W. Fernando and U.S. Amarasinghe/Sri Lanka J. Aquat. Sci. 16 (2011): 01-10

The correlation matrix of morphometric data $O$. mossambicus from Negombo Lagoon and $O$. niloticus from Beira Lake, which were standardized for fish size using equation (2), is given in Table 4. In O. mossambicus, there were 153 pair-wise comparisons and none of the pairs $(0 \%)$ were significantly correlated at 0.05 probability level. Of the 153 comparison of $O$. niloticus, 10 $(6.5 \%)$ pairs were significantly correlated $(\mathrm{p}<0.05)$. They indicate that correlation analyses alone are not sufficient to determine which of the two methods is appropriate to differentiate the two species.

Principal component analysis (PCA) performed for LT/SL transformed morphometric data indicated that $O$. mossambicus and $O$. niloticus could be identified as two clusters (Figure 2). The first three principal components, which had eigen values greater than 1 , explained $42.4 \%$ of overall variance of the data set (Table 5). However, the PCA ordination of LT/SL transformation is inadequate for species differentiation because the PC scores greatly overlap (Figure 2).

In PCA ordination of morphometric characteristics of the two species standardized according to equation 2, first two components explained $85.5 \%$ of overall variance (Table 5) and had eigen value greater than 1 . Therefore, PCA ordination of the first two components (PC1 and PC2) sufficiently described underlying pattern of multivariate data set (Figure 3). It must be noted that PCA employed in the present study was to determine the most appropriate method for morphometric data transformation in $\mathrm{TN}$ analysis so that loading of each variable in PCA was considered redundant.

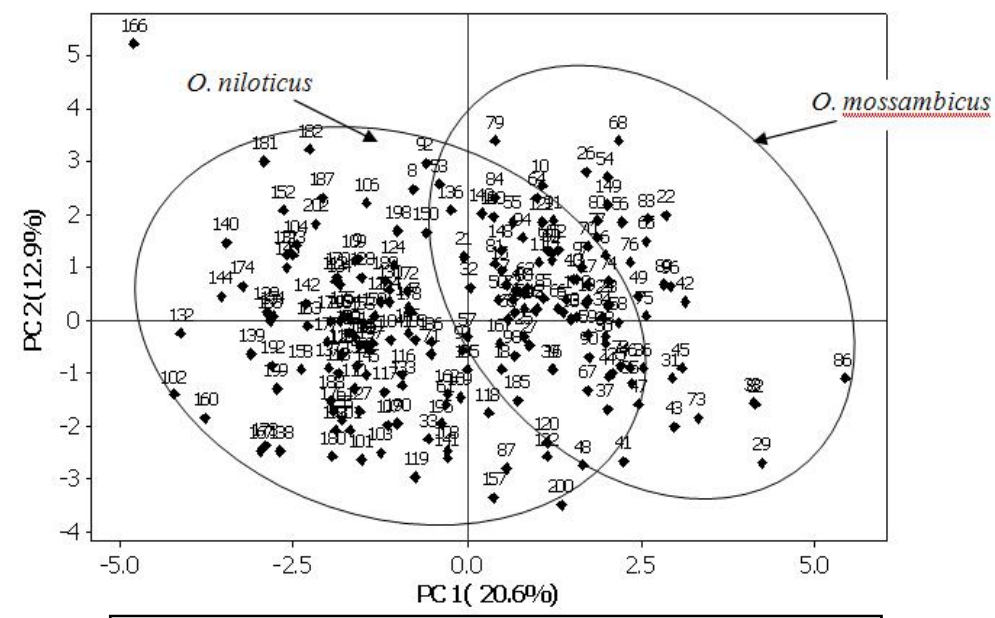

1-100- O. mossambicus, 101-200- O. niloticus

Figure 2. The scatter plot of first two components (PC1 and PC2) of PCA of morphometric data of LT/SL transformation for $O$. mossambicus from Negombo Lagoon and $O$. niloticus from Beira Lake. The clusters of the two species ordinated by PCA are overlapped. 
Table 5. Eigen values, \% variance explained in the first three components (PC1, PC2 and PC3) of principal component analysis of morphometric characteristics of $O$. mossambicus in Negombo Lagoon and $O$. niloticus in Beira Lake transformed using two approaches.

\begin{tabular}{lllllll}
\hline & \multicolumn{3}{l}{$\begin{array}{l}\text { Data transformation by } \\
\text { equation 1 }\end{array}$} & \multicolumn{4}{l}{$\begin{array}{l}\text { Data transformation by } \\
\text { equation 2 }\end{array}$} \\
\cline { 2 - 7 } & PC1 & PC2 & PC3 & PC1 & PC2 & PC3 \\
\hline $\begin{array}{l}\text { Eigen value } \\
\% \text { variance }\end{array}$ & 3.70 & 2.33 & 1.60 & 14.52 & 1.72 & 0.48 \\
$\begin{array}{l}\text { explained } \\
\begin{array}{l}\text { Cumulative \% } \\
\text { variance explained }\end{array}\end{array}$ & 20.6 & 12.9 & 6.9 & 76.4 & 9.0 & 2.6 \\
\hline
\end{tabular}

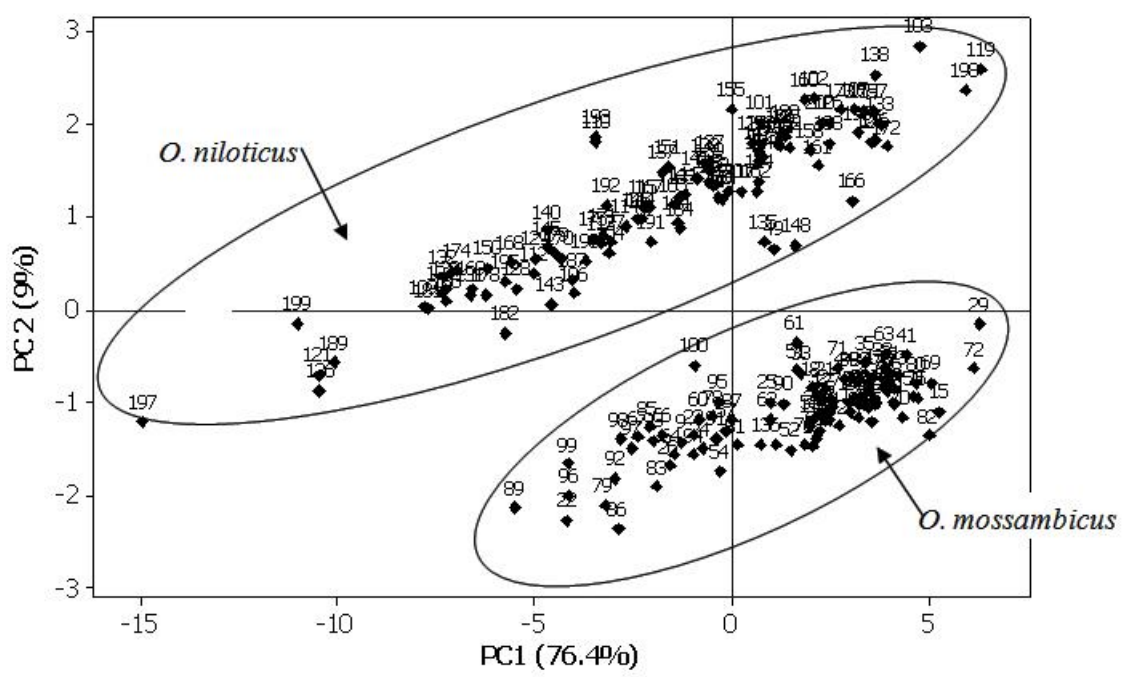

1-100 O. mossambicus, 101-200- O. niloticus

Figure 3. The scatter plot of first two components (PC1 and PC2) of PCA of morphometric data standardized by equation 2 for $O$. mossambicus from Negombo Lagoon and $O$. niloticus from Beira Lake. The clusters of the two species ordinated by PCA are not overlapped

\section{Discussion}

The dominant fish species in the inland fishery of Sri Lanka are $O$. mossambicus and O. niloticus (Amarasinghe 1998; Amarasinghe and Weerakoon 2009). As they are morphologically similar species, simple comparison of morphometric data is not sufficient for describing morphometric variability of the two species. Also, O. mossambicus and $O$. 
niloticus are known to hybrid naturally (Amarasinghe and De Silva 1996) so that hybrid forms might possess mixed characteristics of the two species making it difficult to differentiate using simple morphometric data. The present analysis indicated that TN system could be effectively used for morphological differentiation of the two species.

The use of truss networks has replaced many of the standard morphometric techniques, having the advantage of covering comprehensively the whole of the fish in a series of short segments, measured parallel, perpendicular or obliquely to the principal body axis (Strauss and Bookstein 1982; Turan 1999). This method overcomes limitations associated with traditional techniques used to characterize fish shape, which measure repeatedly along the length of the body axis and tend to cluster around the head (Hockaday et al. 2000).

However, truss morphometric measurements are needed to be standardized for fish size prior to multivariate analysis, to eliminate any size effect in the data set. Of the two data standardization methods, the data transformation method presented by Senar et al. (1994) and Doherty and McCarthy (2004) is found to be more effective than LT/SL transformation.

The two species are difficult to be identified, if not impossible, using phenotypic colour variations because hybrid forms have mixed characteristics (Amarasinghe and De Silva 1996). Hence, multivariate statistical methods are useful tools to be employed to investigate underlying nature of data sets. The PCA with appropriate data standardization employed in this study indicated that the Oreochromis species could be differentiated.

However, there are some limitations in the TN system for morphological analysis. Landmark locations are recorded as two or three-dimensional coordinates resulting in a spatial map of the relative location of the chosen points. Landmarks do not contain information on the spaces, curves, or surface between them. If data concerning regions between landmarks are not part of the data collected, then we cannot expected to obtain verifiable information regarding the aspects of form or form change occurring between landmarks (Richtsmeier et al. 2002). Despite these limitations the TN system can be effectively used for differentiating morphologically similar fish species.

\section{References}

Amarasinghe, U.S. 1998.

Reservoir fisheries management in Sri Lanka: Achievements, mistakes and lessons for future. International Review of Hydrobiology 83: 523530 .

Amarasinghe, U.S. and S.S. De Silva 1996.

Impact of Oreochromis mossambicus x O. niloticus (Pisces: Cichlidae) hybridization on population reproductive potential and long-term influence on a reservoir fishery. Fisheries Management Ecology 3: 239249.

Amarasinghe, U.S. and D.E.M. Weerakoon 2009. 
Present status and future strategies for the management of reservoir fisheries in Sri Lanka. 69-98 pp. In: De Silva, S.S. and U.S. Amarasinghe (eds.), Status of reservoir fisheries in five Asian countries. NACA Monograph No. 2. Network of Aquaculture Centres in AsiaPacific, Bangkok, Thailand. 116p.

De Silva, C.D. and J. Ranasinghe 1989.

Biochemical evidence of hybrid gene introgression in some reservoir populations of tilapia in Southern Sri Lanka. Aquaculture and Fisheries Management 20: 125-133.

De Silva, S.S. 1988.

Reservoirs of Sri Lanka and their fisheries. FAO Fisheries Technical Paper 298: 128pp.

Doherty, D. and T.K. McCarthy 2004.

Morphometric and meristic characteristics analysis of two western Iris populations of Arctic char, Salvelines Alpinus (L.). Biology and Environment: Proceedings of the Royal Irish Academy 148B (1): 75-85.

Hockaday, S., T.A. Beddow, M. Stone, P. Hancock and L.G. Ross 2000.

Using truss networks to estimate the biomass of Oreochromis niloticus, and to investigate shape characteristics. Journal of Fish Biology 57: 9811000 .

Murta, A.G. 2000.

Morphological variation of horse mackerel (Trachurus frachurus) in the Iberian and North African Atlantic: implications for stock identification. ICES Journal of Marine Science 57: 1240-1248.

Parsons, K.J., B. W. Robinson and T. Hrbek 2003.

Getting into shape: An empirical comparison of traditional truss-based morphometric methods with a newer geometric method applied to new world cichlids. Environmental Biology of Fishes 67: 417-431.

Richtsmeier, J.T., V.B. Deleon and S.R. Lele 2002.

The promise of geometric morphometrics. Yearbook of Physical Anthropology 45: 63-91.

Senar, J.C., J. Leonart and N.B. Metcalfe 1994.

Wing-shape variation between resident and transient wintering siskins Carduelis spinus. Journal of Avian Biology 25(1): 50-54.

Strauss, R.E. and F.L. Bookstein 1982.

The truss: Body form reconstructions in morphometrics. Systematic Zoology 31(2): 113-135.

Turan, C. 1999.

A note on the examination of morphometric differentiation among fish populations: The truss system. Journal of Zoology 23: 259-263. 